tain about expanding their role. Attending their monthly meeting in Washington last Friday, they were reluctant to declare themselves in favour of Dr Branscomb's ideas, preferring instead to refer them both to NSB committees and to officials of the foundation for further consideration.

Since their formation shortly after the Second World War, both board and foundation have been the focus of a broad debate over whether they should limit their interest to the basic research programmes for which they shared responsibility; or whether to occupy a more prominent position in national discussions on directions for US science and technology. Two factors in particular seem to have rekindled this debate. First, the apparent decision by President Reagan's science adviser, Dr George A. Keyworth III, not to resurrect the President's Science Advisory Board (PSAC) which performed this broader political role in the 1950s and 1960s until it was abolished by President Nixon in 1973. And second, the feeling that the Office of Science and Technology Policy (OSTP) is so closely tied to the executive responsibilities of the White House that it has little time to think about long-term strategies.

The discussion has been catalysed by a report being prepared for Dr Branscomb by Dr Philip Smith, previously an associate administrator of OSTP, and recently appointed executive officer to the National Academy of Sciences. Addressing the board members at last week's meeting, $\mathrm{Dr}$ Smith said that NSF in particular was in a stronger position than in the past. "The NSF has become a big and mature organization which is respected throughout the world", Dr Smith said. "The time has come to think in terms of what the next steps are for the NSF as an institution; it is an opportunity to reform the foundation and to keep it alive."

Areas in which he suggested that a strong policy initiative might be of value included science and engineering education.

Among the more sceptical board members was its vice-chairman, $\mathrm{Dr}$ Herbert Doan, chairman of a venture capital company and a director of Dow Chemical. He suggested that broad policy statements were of little value without the authority to carry them out.

There was also reluctance by NSF director Dr John Slaughter to be swayed by Dr Branscomb's vision. He suggested that, rather than discussing the roles of the board and the foundation the emphasis should be on improving efficiency.

But Dr Branscomb was insistent. "I would urge the director [of NSF] not to underestimate the prestige of his of fice and the impact that he can have,"' he said. Dr Branscomb emphasized that he was not suggesting that NSB could, or should, take on the mantle of PSAC. But he supported Dr Smith's contention that many professional research societies and industrial research organizations "are looking for some entity on the Washington scene to provide leadership that has been lacking in recent years"'.

David Dickson

\section{Bazan explains escape from Argentina}

Dr Nicolas Bazan, a leading expert on epilepsy, has now made known the circumstances surrounding his dismissal last March from his posts as director of the Argentinian Institute of Biochemical Research at Bahia Blanca and of Professor of Biological Biochemistry at the University of the South (see Nature 14 May, p.100) Professor Bazan explained his situation to fellow neurochemists while visiting Britain for the International Neurochemistry Conference in Nottingham, which included a special session on the state of academic freedom and human rights in South America.

Dr Bazan was informed of his dismissal last March. The letters of dismissal were dated 30 December - the day before emergency legislation empowering the government to make such dismissals was due to expire. Dr Bazan, however, suggested that the dismissal notices had been back-dated, since, in the intervening period, he had been allowed to travel to the United States for a meeting of the American Society of Neurochemists, and foreign travel is not normally permitted to Argentinian academics in bad standing with the government.

\section{Cigarette smoking Hope for habitués}

Making cigarettes a more effective means of delivering their main pharmacological agent, nicotine, is the latest suggestion from the Tobacco Advisory Council for reducing the health risks of smoking.

A new publication, Monograph on the Pharmacology and Toxicology of Nicotine, sets out to examine the properties of nicotine itself rather than nicotine plus the various other components of cigarette smoke. The authors conclude that at the levels present in cigarette smoke nicotine is less toxic than many of the other smoke components, and that there is no conclusive evidence that nicotine contributes to the carcinogenic potential of cigarette smoke.

The trend towards lower tar and lower nicotine cigarettes does seem to be associated with a reduced death rate due to lung cancer. But many smokers subconsciously adjust their smoking patterns to restore their nicotine intake to their previous accustomed dose. So for them at

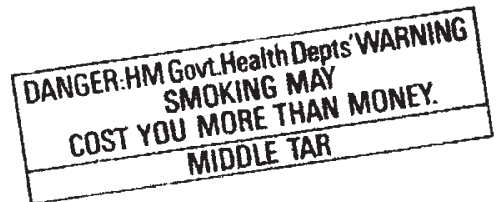

least, low-tar but medium-nicotine cigarettes might be the "cleanest" way of obtaining the dose of nicotine they feel they need, while minimizing the amounts of carcinogens and other toxins that they take in. So this new report should encourage cigarette manufacturers to continue looking for ways of increasing the amounts of nicotine that can be squeezed into a cigarette without increasing tar levels - a task that so far can only be done using rather expensive techniques.

Although reaffirming the notion that no cigarettes are safe, anti-smoking proponents are unlikely to take exception to the idea of finding a new balance of ingredients that may put confirmed smokers slightly less at risk than they are now. But the Tobacco Advisory Council monograph does include some points likely to be hotly disputed. For instance, although the medical profession is adamant in saying that pregnant women should not smoke, the authors state "... evidence is available showing that maternal smoking is not associated with the risk of developing fetal malformations". Strictly true that may be, but maternal smoking is associated with reduced fetal growth and low birth weight, increased spontaneous abortion, complications in pregnancy and increased perinatal mortality.

Charles Wenz

- Monograph on the Pharmacology and Toxicology of Nicotine by A.J. Cohen \& F.J.C. Roe is published by the Tobacco Advisory Council, London, at $£ 5.00$. 